\title{
Métodos de fornecimento de nitrogênio para melhorar a produtividade na cultura do feijoeiro irrigado no Cerrado Mato-grossense
}

\author{
Anderson LANGE ${ }^{1,3 *}$, Edilson CAVALLI ${ }^{2}$, Ewerton Alves CARLETO ${ }^{3}$, Antonio Carlos BUCHELT ${ }^{4}$, \\ Cassiano CAVALLI ${ }^{2}$, Cassiano Spaziani PEREIRA ${ }^{1,3}$
}

\author{
${ }^{1}$ Programa de Pós-Graduação em Agronomia, Universidade Federal de Mato Grosso, Sinop, MT, Brasil. \\ ${ }^{2}$ Programa de Pós-Graduação em Agricultura Tropical e Subtropical, Instituto Agronômico de Campinas, Campinas, SP, Brasil. \\ ${ }^{3}$ Instituto de Ciências Agrárias e Ambientais, Universidade Federal de Mato Grosso, Sinop, MT, Brasil. \\ ${ }^{4}$ Programa de Pós-Graduação em Agronomia (Ciência do Solo), Universidade Estadual Paulista, Jaboticabal, SP, Brasil. \\ *E-mail: paranalange@hotmail.com
}

Recebido em maio/2017; Aceito em agosto/2017.

\begin{abstract}
RESUMO: O nitrogênio é um dos elementos mais requerido pela cultura do feijoeiro e seu fornecimento à planta pode se dar por meio de adubação nitrogenada e por meio da fixação biológica. O presente estudo objetivou avaliar estratégias de manejo da adubação nitrogenada e a capacidade da associação entre inoculante e $\mathrm{Co}+\mathrm{Mo}$ em substituir parcialmente o $\mathrm{N}$ aplicado na cultura do feijoeiro semeado em sistema irrigado. $\mathrm{O}$ estudo foi desenvolvido em Sinop - MT, no período de junho a outubro de 2011, época denominada inverno, sob pivô central em sistema de semeadura direta, em um Latossolo Vermelho-amarelo Distrófico. O delineamento experimental utilizado foi de blocos casualizados com 15 tratamentos e 4 repetições. Os tratamentos foram constituídos pela combinação de doses e fontes de N, inoculação com Rhizobium tropicci e tratamento de sementes com Co e Mo. Em relação aos tratamentos não se observou diferença para altura da inserção da primeira vagem e número de grãos por vagem. A produtividade foi maior nos tratamentos que receberam N. A associação da inoculação com baixas doses de N é efetiva para suprir as demandas da cultura, se igualando a elevadas doses de N. A produtividade apresentou correlação positiva e significativa com a maioria das características avaliadas.
\end{abstract}

Palavras-chave: Phaseolus vulgaris, manejo do nitrogênio, semeadura direta na palha, fixação biológica de nitrogênio, cultivo de inverno.

\section{Methods of supply of nitrogen to improve productivity in the culture of irrigated beans in savanna mato-grossense}

\begin{abstract}
Nitrogen is one of the elements most required by the bean crop and its supply to the plant can occur through nitrogen fertilization and through biological fixation. The objective of this study was to evaluate strategies of nitrogen fertilization management and the ability of the association between inoculant and Co + Mo to partially replace the $\mathrm{N}$ applied in the bean crop planted in irrigated system. The study was developed in Sinop-MT, from June to October 2011, a period denominated winter, under central pivot in a no-tillage system, in a Red-yellow Latosol. The experimental design was a randomized block with 15 treatments and 4 replicates. The treatments consisted of the combination of rates and sources of $\mathrm{N}$, inoculation with Rhizobium tropicci and treatment of seeds with Co and Mo. Regarding the treatments, no difference was observed in the height of the first pod insertion and number of grains per pod. The productivity was higher in the treatments that received $\mathrm{N}$. The association of the inoculation with low rates of $\mathrm{N}$ is effective to meet the demands of the crop, equaling to high rates of $\mathrm{N}$. The productivity showed a positive and significant correlation with most of the evaluated characteristics.
\end{abstract}

Keywords: Phaseolus vulgaris, management of nitrogen, direct sowing in straw, biological nitrogen fixation, winter cropping.

\section{INTRODUÇÃO}

O feijão comum (Phaseolus vulgaris L.) é um dos alimentos mais consumidos, sendo fonte proteica da dieta brasileira, e um alimento produzido principalmente pela agricultura familiar. Deste modo se tem poucos investimentos na cultura, que ainda apresenta baixa produtividade, vinculada a vários fatores como baixa tecnificação, cultivares impróprios às condições regionais de clima e solo, adubações inadequadas entre outros.

No estado de Mato Grosso a cultura tem despertado atenção de grandes produtores, pois o mesmo pode ser cultivado em terceira safra, sob irrigação, trazendo maior retorno econômico ao produtor, já que os preços nessa época são favoráveis e consegue-se um melhor manejo fitossanitário para a cultura.

O cultivo irrigado possibilita a terceira safra ou safra de inverno, podendo resultar em incrementos significativos de renda ao produtor e promover inclusive o aumento da fertilidade pelas adubações sucessivas. Isto vem de encontro às características do feijoeiro, que tem o sistema radicular pequeno, pouco profundo e apresenta ciclo curto, demandando alta quantidade de nutrientes num curto período 
de tempo, o que o torna uma cultura exigente em nutrientes (ALMEIDA et al., 2000).

$\mathrm{O}$ nitrogênio $(\mathrm{N})$ é o nutriente mais requerido pelo feijoeiro e o frequente aparecimento de sintomas de deficiência deste elemento nas lavouras tem gerado questionamentos sobre a melhor fonte, dose e época de aplicação (FARINELLI; LEMOS, 2010). Existem três formas de fornecimento de $\mathrm{N}$ ao feijoeiro: fertilização com adubos nitrogenados, mineralização da matéria orgânica do solo e por meio da fixação biológica de nitrogênio, sendo a primeira a mais usual nos cultivos sob pivô.

Mesmo com grande utilização de adubos nitrogenados na cultura estudos são necessários para se obter uma recomendação, isto devido a eficiência do uso da adubação nitrogenada ser afetada por fatores como fonte, dose e o método de aplicação (BARBOSA FILHO; SILVA, 2001). Ainda os mesmos autores constataram um aumento de produtividade devido ao parcelamento da aplicação de $\mathrm{N}$, corroborando com Farinelli; Lemos (2010) e Cavalli et al. (2016) com trabalho conduzido na mesma região, e que discorda dos resultados obtidos por Binotti (2007) e Gomes Junior et al. (2008).

Uma alternativa a adubação mineral de $\mathrm{N}$ é a utilização de organismos simbióticos que fornecem $\mathrm{N}$ ao feijoeiro, sendo um tema muito controverso na literatura, tendo-se resultados que vão desde a substituição total do $\mathrm{N}$ mineral em cobertura pela inoculação (FERREIRA et al., 2000), ou incrementos na produtividade com a inoculação associada a adubação mineral (LANGE et al., 2017) e ainda ausência de eficiência alguma sobre a produtividade (BASSAN et al., 2001).

Além da alta demanda de $\mathrm{N}$ pela cultura, outros dois elementos são essenciais para que se tenha um bom aproveitamento do $\mathrm{N}$ fixado na FBN, o cobalto (Co) que é indispensável para a síntese da cobalamina (Vitamina B12), que atua nas reações metabólicas para a formação da leghemoglobina, a qual regula a concentração de oxigênio nos nódulos impedindo a inativação da enzima nitrogenase (CERETTA et al., 2005), e o Molibdênio (Mo), que relaciona-se com a atividade da enzima redutase do nitrato, indispensável para um bom aproveitamento do nitrato absorvido pela planta no processo de assimilação do $\mathrm{N}$. Lange et al. (2017) observaram aumento na produtividade quando foi realizada a aplicação conjunta de inoculante, Co, Mo e N, sendo a aplicação conjunta recomendada, pois o custo, principalmente com os micronutrientes e inoculante, é baixo e se paga.

No complexo sistema de aproveitamento de $\mathrm{N}$ pela planta, o enxofre (S) tem grande importância, pois faz parte de vários processos enzimáticos, constituinte de aminoácidos, sendo a adubação sulfatada importante para seu desenvolvimento (MALAVOLTA et al., 1997). Outra vantagem da aplicação de $\mathrm{N}$ associada a $\mathrm{S}$ é que a perda por volatilização do $\mathrm{N}$ derivado da ureia pode ser reduzida em até $20 \%$, quando a ureia é mistura com ao sulfato de amônio (VITTI et al., 2002).

A adubação nitrogenada contribui com grande parte do custo de produção da cultura do feijoeiro, com grande variação entre a eficiência das fontes utilizadas. Uma estratégia promissora é a associação de baixas doses de adubos nitrogenados, com a inoculação combinada com o uso de $\mathrm{Co}+\mathrm{Mo}$, pois propiciam ganhos na produção com baixo custo. Sendo as respostas vinculadas a condições locais de clima e solo, assim é importante o estudo em diferentes regiões. $\mathrm{O}$ trabalho teve como objetivo avaliar estratégias de manejo da adubação nitrogenada e a capacidade da associação entre inoculante e $\mathrm{Co}+\mathrm{Mo}$ em substituir parcialmente o $\mathrm{N}$ aplicado na cultura do feijoeiro semeado em sistema irrigado.

\section{MATERIAL E MÉTODOS}

O experimento foi realizado no município de Sinop (MT) entre junho e outubro de 2011, sob pivô central em sistema de semeadura direta (SSD) conduzido na fazenda JF, (345 m de altitude). O clima da região é classificado como Aw, segundo a classificação de Köppen, com estação seca bem definida, sendo caracterizada pela estiagem rigorosa e período chuvoso bastante intenso. Durante o período de cultivo não ocorreram chuvas e as temperaturas máxima, mínima e média foram $34^{\circ} \mathrm{C}, 18^{\circ} \mathrm{C}$ e $26^{\circ} \mathrm{C}$ respectivamente (Estação Climatológica, UFMT/Sinop).

Antes da implantação do experimento, foram coletadas 15 amostras simples de solo para compor uma amostra composta na camada de $0-0,20 \mathrm{~m}$. Após analisada, os resultados foram: $\mathrm{pH}($ água $)=5,35 ; \mathrm{P}($ Mehl $)=18,40 \mathrm{mg} \mathrm{dm}^{-3} ; \mathrm{K}$ $($ Mehl $)=58,00 \mathrm{mg} \mathrm{dm}^{-3} ; \mathrm{S}=21,8 \mathrm{mg} \mathrm{dm}^{-3} ; \mathrm{Ca}=1,99 \mathrm{cmol}_{\mathrm{c}}$ $\mathrm{dm}^{-3} ; \mathrm{Mg}=0,51 \mathrm{cmol}_{\mathrm{c}} \mathrm{dm}^{-3} ; \mathrm{Al}=0,16 \mathrm{cmol}_{\mathrm{c}} \mathrm{dm}^{-3} ; \mathrm{H}+\mathrm{Al}=$ $5,75 \mathrm{cmol}_{\mathrm{c}} \mathrm{dm}^{-3} ; \mathrm{B}=0,48 \mathrm{mg} \mathrm{dm}^{-3} ; \mathrm{Cu}=1,10 \mathrm{mg} \mathrm{dm}^{-3} ; \mathrm{Fe}=$ $190 \mathrm{mg} \mathrm{dm}^{-3} ; \mathrm{Mn}=15,05 \mathrm{mg} \mathrm{dm}^{-3} ; \mathrm{Zn}=8,90 \mathrm{mg} \mathrm{dm}^{-3}$; CTC a pH 7,0 =8,39 $\mathrm{cmol}_{\mathrm{c}} \mathrm{dm}^{-3} ; \mathrm{V}=31,57 \%, \mathrm{MO}=30,00 \mathrm{~g} \mathrm{~kg}^{-1}$ e a textura classificada como argilosa. O solo da área experimental foi classificado como Latossolo VermelhoAmarelo Distrófico.

O delineamento experimental foi de blocos casualizados (DBC) com 15 tratamentos e 4 repetições, testando combinações de $\mathrm{N}$ (épocas, doses e fontes), enxofre (S), inoculante (I) e micronutrientes (Co e Mo) (Tabela 1). As fontes utilizadas foram; ureia $(44 \%$ de $\mathrm{N})$, sulfato de amônio ( $20 \%$ de $\mathrm{N}$ e $24 \%$ de $\mathrm{S})$, produto comercial Co-Mo $(1,5 \%$ ou $24,15 \mathrm{~g} \mathrm{~L}^{-1}$ de $\mathrm{Co}$ e $15 \%$ ou $241,5 \mathrm{~g} \mathrm{~L}^{-1}$ de Mo) utilizado no tratamento de sementes. Foi utilizado o inoculante Rizobhium tropicci (SEMIA 4088 - 1,10 x 109 células viáveis de rizóbio $\mathrm{g}^{-1}$ de inoculante), sendo aplicado no momento da semeadura, via semente, com uma dose de $0,3 \mathrm{~kg}$ para $50 \mathrm{~kg}$ de semente. Conforme indicação do fornecedor utilizou-se solução de sacarose a $10 \%$ para melhorar a aderência.

A cultivar utilizada foi a Jalo Precoce, resultado do melhoramento genético da cultivar Goiano Precoce, material do grupo comercial chamado de Manteigão (tipo Jalo). As parcelas experimentais de $3 \times 3 \mathrm{~m}$, foram riscadas manualmente com enxada e a semeadura foi manual no espaçamento de $0,5 \mathrm{~m}$ entre linhas totalizando 6 linhas por parcela, numa profundidade de aproximadamente $3 \mathrm{~cm}$, com 15 sementes por metro, sob a palhada do milho safrinha, em 23/06/2011

A adubação de base foi $80 \mathrm{~kg} \mathrm{ha}^{-1}$ de $\mathrm{P}_{2} \mathrm{O}_{5}$, na forma de superfosfato triplo $\left(48 \%\right.$ de $\left.\mathrm{P}_{2} \mathrm{O}_{5}\right)$ e $60 \mathrm{~kg} \mathrm{ha}^{-1} \mathrm{~K}_{2} \mathrm{O}$, na forma de cloreto de potássio $\left(60 \%\right.$ de $\left.\mathrm{K}_{2} \mathrm{O}\right)$ aplicado em todo o experimento na superfície, após a semeadura. As adubações com $\mathrm{N}$ e $\mathrm{S}$ seguiram as doses de cada tratamento, sendo aplicadas manualmente em superfície e em área total. Após a semeadura e a adubação de base, aplicou-se uma lâmina de $20 \mathrm{~mm}$ de água, para incorporar o fertilizante nitrogenado, 
assim diminuindo as perdas por volatilização (STONE; MOREIRA, 2001).

$\mathrm{A}$ adubação de cobertura com $\mathrm{N}$ foi realizada aos 30 dias após emergência (DAE), aplicando-se manualmente o adubo, de acordo com cada tratamento, situação em que se repetiu a irrigação conforme acima citado. A lâmina diária de irrigação foi de aproximadamente $5 \mathrm{~mm}$.

Tabela 1. Manejo adotado para o nitrogênio $(\mathrm{N})$, enxofre (S), cobalto (Co), molibdênio (Mo) e inoculação (I) aplicado na semeadura e em cobertura na cultura do feijoeiro comum. Sinop - MT, 2011.

Table 1. Management of nitrogen (N), sulfur (S), cobalt (Co), molybdenum (Mo) and inoculation (I) applied to sowing and cover in common bean crop. Sinop - MT, 2011.

\begin{tabular}{|c|c|c|c|c|c|c|c|c|}
\hline \multirow[t]{3}{*}{ Tratamentos } & \multicolumn{4}{|c|}{.Adubação de Base.......... } & \multicolumn{2}{|c|}{ Adubação de cobertura } & \multicolumn{2}{|c|}{ Adubação total } \\
\hline & I & $\mathrm{N}$ & $\mathrm{S}$ & $\mathrm{Co}+\mathrm{Mo}$ & $\mathrm{N}$ & $\mathrm{S}$ & $\mathrm{N}$ & $\mathrm{S}$ \\
\hline & & \multicolumn{2}{|c|}{$\left(\mathrm{kg} \mathrm{ha}^{-1}\right)$} & $\left(5+50 \mathrm{~g} \mathrm{ha}^{-1}\right)$ & \multicolumn{2}{|c|}{$\ldots \ldots\left(\mathrm{kg} \mathrm{ha}^{-1}\right) \ldots \ldots$} & \multicolumn{2}{|c|}{$\ldots \ldots\left(\mathrm{kg} \mathrm{ha}^{-1}\right) \ldots}$. \\
\hline $\mathrm{T} 1$ & Não & 0 & 0 & Não & 0 & 0 & 0 & 0 \\
\hline T2 & Não & 100 & 0 & Não & 0 & 0 & 100 & 0 \\
\hline T3 & Não & 60 & 0 & Não & 40 & 24 & 100 & 24 \\
\hline T4 & Não & 40 & 0 & Não & 60 & 24 & 100 & 24 \\
\hline T5 & Não & 20 & 0 & Não & 80 & 24 & 100 & 24 \\
\hline T6 & Não & 40 & 0 & Não & 80 & 24 & 120 & 24 \\
\hline $\mathrm{T} 7$ & Não & 40 & 0 & Não & 60 & 0 & 100 & 0 \\
\hline $\mathrm{T} 8$ & Sim & 0 & 0 & Não & 0 & 0 & 0 & 0 \\
\hline T9 & Sim & 0 & 0 & Sim & 0 & 0 & 0 & 0 \\
\hline $\mathrm{T} 10$ & Sim & 20 & 0 & Sim & 0 & 0 & 20 & 0 \\
\hline T11 & Sim & 20 & 0 & Sim & 20 & 24 & 40 & 24 \\
\hline $\mathrm{T} 12$ & Sim & 40 & 24 & Sim & 0 & 0 & 40 & 24 \\
\hline $\mathrm{T} 13$ & Sim & 20 & 0 & Sim & 60 & 24 & 80 & 24 \\
\hline T14 & Sim & 20 & 0 & Sim & 40 & 0 & 60 & 0 \\
\hline T15 & Não & 60 & 0 & Não & 100 & 0 & 160 & 0 \\
\hline
\end{tabular}

Foram realizadas três leituras de clorofila utilizando um clorofilômetro portátil da marca FALKER - CFL 1030, a qual foi realizada aos 20, 35 e aos 50 DAE respectivamente, sendo realizadas entre $14 \mathrm{~h} 00$ e $16 \mathrm{~h} 00$, em três pontos da parcela, sendo que em cada ponto as leituras foram efetuadas em duas plantas, sendo feitas cinco leituras por folha (penúltima folha trifoliada completamente desenvolvida), em todo o limbo da folha, exceto nervuras, somando, assim, 30 leituras por parcela, totalizando, portanto, 120 leituras por tratamento, segundo metodologia adaptada de Barbosa Filho et al. (2008). O índice de suficiência de nitrogênio (ISN) foi encontrado pela fórmula recomendada pelo fabricante (Equação 1).

$$
\mathrm{ISN}=\left(\mathrm{M}_{\mathrm{pa}} / \mathrm{M}_{\mathrm{pr}}\right) * 100
$$

(Equação 1)

em que: ISN = índice de suficiência de nitrogênio, $\mathrm{M}_{\mathrm{pa}}=$ Média das Medições na parcela avaliada e $\mathrm{M}_{\mathrm{pr}}=$ Média das Medições na parcela Referência.

No presente estudo adotou-se que os valores críticos de ISN iguais $90 \%$ de produtividade máxima, abaixo dos quais há indicação de que possa haver resposta à aplicação de $\mathrm{N}$ suplementar, conforme Barbosa Filho et al. (2009), e o tratamento padrão para a leitura aos $20 \mathrm{DAE}$ foi o T2 com $100 \mathrm{~kg} \mathrm{ha}^{-1}$ de $\mathrm{N}$ na semeadura, para as leituras aos 35 e 50 DAE foi o tratamento T15 com $160 \mathrm{~kg} \mathrm{ha}^{-1}$ de $\mathrm{N}$ (60 na semeadura +100 em cobertura).

No pré-florecimento, foram coletadas, ao acaso, as últimas folhas trifolioladas completamente expandida de dez plantas dentro da área útil das parcelas, secas na estufa de fluxo de ar a de $65^{\circ} \mathrm{C}$ por 72 horas e posteriormente, moídas e seu teor de $\mathrm{N}$ (NF), determinado conforme método de digestão sulfúrica seguida de destilação Kjeldahl (SILVA, 2009).

A colheita foi realizada manualmente, após a cultura atingir a maturidade fisiológica, sendo colhidos $4 \mathrm{~m}^{2}$ (área útil) no centro de cada parcela. Dentro da área útil foram selecionadas 10 plantas aleatoriamente por parcela para as seguintes avaliações: altura de plantas (AP); altura da inserção da primeira vagem (IPV); número de grãos por vagem $(\mathrm{GV})$; número de vagens por planta (VP); massa de 100 grãos (M100) e massa de plantas inteiras secas (MS). Após a determinação da massa seca, as plantas livres dos grãos foram moídas para determinar o seu teor de N (NP) pelo método Kjeldahl (SILVA, 2009).

Após a colheita da área útil as plantas foram trilhadas em trilhadeira mecânica para obtenção da produtividade (PD), sendo a massa dos grãos das plantas selecionadas para demais avaliações somada a massa final, ambas com umidade ajustada a $13 \%$. Nesta ocasião foram separadas amostras de grãos de cada parcela para determinação do teor de $\mathrm{N}$ nos grãos $(\mathrm{NG})$ e também para determinar a exportação de $\mathrm{N}$ pela cultura $(\mathrm{EN})$.

A eficiência do uso de nitrogênio foi estimada segundo método proposto por Fageria; Baligar (2005), por meio do cálculo da eficiência agronômica (EA) (Equação 2).

$$
\mathrm{EA}=\left(\mathrm{PG}_{\mathrm{cf}}-\mathrm{PG}_{\mathrm{sf}}\right) / \mathrm{QNa}
$$

em que: $\mathrm{EA}$ = eficiência agronômica expressa em $\mathrm{kg}$ grãos por $\mathrm{kg}^{-1} \mathrm{~N}$ aplicado, $\mathrm{PG}_{\mathrm{cf}}=$ produtividade de grãos com fertilizante nitrogenado, $\mathrm{PG}_{\mathrm{sf}}=$ produtividade de grãos sem fertilizante nitrogenado e $\mathrm{QNa}=$ quantidade de nitrogênio aplicado em $\mathrm{kg} \mathrm{ha}^{-1}$.

Os dados foram avaliados através de variância simples, sendo comparadas pelo teste de F. As médias foram comparadas pelo teste de Scott-Knott e realizado contrastes ortogonais para a produtividade de grãos no nível de $5 \%$ de probabilidade. Realizaram-se, ainda os cálculos do coeficiente de correlação de Pearson (r), para verificar a correlação dos dados. 


\section{RESULTADOS}

3.1 Parâmetros agronômicos.

A altura de inserção da primeira vagem e número de grãos por vagem foram os únicos fatores que não mostraram diferenças entre os tratamentos (Tabela 2). Observa-se que altura de planta e altura de inserção de primeira vagem são variáveis independentes sendo que uma não interfere na outra, demostrando baixa correlação linear (Tabela 6).

Tabela 2. Altura de plantas (AP); inserção da primeira vagem (IPV); número de vagens por planta (VP); número de grãos por vagens (GV); massa de 100 grãos (M100); massa seca da planta inteira (MS) e produtividade (PD), no sistema de cultivo do pivô central, em plantas de feijoeiro Jalo precoce sobre diferentes tratamentos. Fazenda JF, Sinop-MT, 2011

Table 2. Height of plants (AP); Insertion of the first pod (IPV); Number of pods per plant (VP); Number of beans per pod (GV); Mass of 100 grains (M100); Dry mass of whole plants (MS) and productivity (PD), in the central pivot system, in Jalo precoce bean plants on different treatments. Fazenda JF, Sinop-MT, 2011.

\begin{tabular}{|c|c|c|c|c|c|c|c|}
\hline \multirow{2}{*}{ Tratamentos } & AP & IPV & VP & GV & M100 & MS & \multirow{2}{*}{$\frac{\text { PD }}{\left(\mathrm{kg} \mathrm{ha}^{-1}\right)}$} \\
\hline & \multicolumn{2}{|c|}{$\ldots \ldots \ldots .(\mathrm{cm}) \ldots \ldots \ldots$} & \multicolumn{2}{|c|}{....(Quantidade).... } & \multicolumn{2}{|c|}{$\ldots \ldots \ldots \ldots \ldots . .(\mathrm{g}) \ldots \ldots \ldots \ldots \ldots$} & \\
\hline T1 & $45,93 \mathrm{~b}$ & $17,90^{\mathrm{ns}}$ & $6,58 \mathrm{~b}$ & $3,80^{\mathrm{ns}}$ & $32,26 \mathrm{~b}$ & $9,33 \mathrm{~b}$ & $1226,17 \mathrm{~b}$ \\
\hline $\mathrm{T} 2$ & $58,90 \mathrm{a}$ & 18,13 & $13,35 \mathrm{a}$ & 3,86 & $31,62 \mathrm{~b}$ & $16,10 \mathrm{a}$ & $2108,32 \mathrm{a}$ \\
\hline $\mathrm{T} 3$ & $57,53 \mathrm{a}$ & 18,60 & $9,65 \mathrm{~b}$ & 4,16 & $31,94 \mathrm{~b}$ & $14,07 \mathrm{a}$ & $2168,27 \mathrm{a}$ \\
\hline $\mathrm{T} 4$ & $64,25 \mathrm{a}$ & 19,48 & $11,95 \mathrm{a}$ & 3,74 & $31,86 \mathrm{~b}$ & $14,65 \mathrm{a}$ & $1882,98 \mathrm{a}$ \\
\hline $\mathrm{T} 5$ & $55,03 \mathrm{~b}$ & 17,78 & $8,83 \mathrm{~b}$ & 4,26 & $31,65 \mathrm{~b}$ & $12,25 \mathrm{~b}$ & $1718,40 \mathrm{~b}$ \\
\hline T6 & $65,48 \mathrm{a}$ & 16,13 & $16,18 \mathrm{a}$ & 4,07 & 33,99 a & $16,37 \mathrm{a}$ & $2383,06 \mathrm{a}$ \\
\hline $\mathrm{T} 7$ & $71,63 \mathrm{a}$ & 20,05 & $11,93 \mathrm{a}$ & 3,91 & $31,20 \mathrm{~b}$ & $13,70 \mathrm{a}$ & $1939,44 \mathrm{a}$ \\
\hline $\mathrm{T} 8$ & $50,68 \mathrm{~b}$ & 19,15 & $8,23 \mathrm{~b}$ & 3,75 & $30,72 \mathrm{~b}$ & $9,39 \mathrm{~b}$ & $1247,56 \mathrm{~b}$ \\
\hline T9 & $51,25 \mathrm{~b}$ & 20,73 & $6,33 \mathrm{~b}$ & 3,83 & $30,64 \mathrm{~b}$ & $8,61 \mathrm{~b}$ & $1364,42 b$ \\
\hline $\mathrm{T} 10$ & $63,73 \mathrm{a}$ & 19,65 & $10,05 \mathrm{~b}$ & 3,79 & $31,86 \mathrm{~b}$ & $14,66 \mathrm{a}$ & $1786,39 \mathrm{~b}$ \\
\hline $\mathrm{T} 11$ & $61,73 \mathrm{a}$ & 20,83 & $7,80 \mathrm{~b}$ & 4,16 & $31,55 \mathrm{~b}$ & $12,39 \mathrm{~b}$ & $1552,49 \mathrm{~b}$ \\
\hline $\mathrm{T} 12$ & $60,53 \mathrm{a}$ & 19,43 & $9,43 \mathrm{~b}$ & 3,66 & $29,64 \mathrm{~b}$ & $13,86 \mathrm{a}$ & $1725,36 \mathrm{~b}$ \\
\hline $\mathrm{T} 13$ & $62,03 \mathrm{a}$ & 21,28 & $8,83 \mathrm{~b}$ & 3,89 & 33,27 a & $12,49 \mathrm{~b}$ & $1692,62 \mathrm{~b}$ \\
\hline $\mathrm{T} 14$ & $58,55 \mathrm{a}$ & 18,43 & $8,75 \mathrm{~b}$ & 4,15 & $31,43 \mathrm{~b}$ & $11,53 \mathrm{~b}$ & $1788,32 \mathrm{~b}$ \\
\hline $\mathrm{T} 15$ & $65,55 \mathrm{a}$ & 19,25 & $13,64 \mathrm{a}$ & 3,82 & $34,42 \mathrm{a}$ & $16,45 \mathrm{a}$ & $2298,53 \mathrm{a}$ \\
\hline $\mathrm{CV}(\%)$ & 12,98 & 11,51 & 26,48 & 9,58 & 4,42 & 23,11 & 21,24 \\
\hline Média & 59,52 & 19,12 & 10,10 & 3,92 & 31,87 & 13,05 & 1792,16 \\
\hline
\end{tabular}

${ }^{\text {ns }}$ não significativo. As médias seguidas de mesma letra nas colunas, não diferem entre si pelo teste de Scott-Knott a 5\% de probabilidade.

${ }^{n s}$ not significant. The averages followed by the same letter in the columns do not differ by Scott-Knott's test at $5 \%$ probability.

A altura de planta foi influenciada pela aplicação de $\mathrm{N}$ e o tratamento Controle, T8 (I) e T9 (I+Co+Mo) apresentaram plantas menores, com 45,92; 50,67 e $51,25 \mathrm{~cm}$ respectivamente. $\mathrm{O}$ tratamento $\mathrm{T} 5\left(20 \mathrm{~kg} \mathrm{ha}^{-1} \mathrm{de} \mathrm{N}\right.$ na base e $80 \mathrm{~kg} \mathrm{ha}^{-1} \mathrm{de} \mathrm{N}+24 \mathrm{~kg} \mathrm{ha}^{-1}$ de $\mathrm{S}$ em cobertura) foi o único tratamento que recebeu a adubação nitrogenada e foi inferior aos demais tratamentos que também receberam $\mathrm{N}$.

$\mathrm{O}$ número total de vagens por planta foi influenciado pela aplicação de $\mathrm{N}$ na base, bem como com o total de $\mathrm{N}$ aplicado, sendo os melhores resultados para a adubação total superior a $100 \mathrm{~kg} \mathrm{ha}^{-1}$, com aplicação de pelo menos $40 \%$ na base, o único tratamento que respondeu de forma diferente foi o T3 $\left(60 \mathrm{~kg} \mathrm{ha}^{-1}\right.$ de N na base e $40 \mathrm{~kg} \mathrm{ha}^{-1} \mathrm{de} \mathrm{N}+24 \mathrm{~kg} \mathrm{ha}^{-1}$ de S em cobertura) que apresentou resposta inferior aos demais tratamentos com quantidade de $\mathrm{N}$ e forma de aplicação semelhante.

Quanto à massa seca de plantas inteiras, observa-se relação direta com a altura de planta mantendo a mesma distribuição (Tabela 6), mesmo a tendência sendo a mesma, para a variável altura de planta apenas os tratamentos foram estatisticamente inferiores, enquanto a massa seca ouve maior variação nos resultados. Os tratamentos T10 (inoculado +20 $\mathrm{kg} \mathrm{ha}^{-1}$ de N na base + CoMo) e T12 (inoculado $+40 \mathrm{~kg} \mathrm{ha}^{-1}$ de $\mathrm{N}$ e $24 \mathrm{~kg} \mathrm{ha}^{-1}$ de S na base + CoMo) apresentaram massa seca equivalente aos tratamentos que receberam altas doses de $\mathrm{N}$, por outro lado o tratamento $\mathrm{T} 5\left(20 \mathrm{~kg} \mathrm{ha}^{-1} \mathrm{de} \mathrm{N}\right.$ na base e $80 \mathrm{~kg} \mathrm{ha}^{-1} \mathrm{de} \mathrm{N}+24 \mathrm{~kg} \mathrm{ha}^{-1}$ de S em cobertura).

As maiores médias de massa de 100 grãos foram T13, T6 e T15 com 33,26, 33,98, 34,42 g respectivamente, sendo estes superiores aos demais tratamentos, os tratamentos T6 e T15 são tratamentos com doses elevadas $\left(120\right.$ e $160 \mathrm{~kg} \mathrm{ha}^{-1}$ respectivamente) já o T13 recebeu a dose acumulada de apenas $80 \mathrm{~kg} \mathrm{ha}^{-1}$ de $\mathrm{N}$.

A produtividade foi influenciada pela adubação nitrogenada e as menores médias foram para os tratamentos T1, T8 e T9 que não receberam $\mathrm{N}$ (Tabela 3). Os tratamentos com adubação acima de $100 \mathrm{~kg} \mathrm{ha}^{-1}$ apresentaram as maiores produtividades, se comparando aos demais tratamentos que receberam N. Os tratamentos que receberam a inoculação (T8 e T9) tiveram médias iguais ao controle (T1), demonstrado que a inoculação por si só não beneficia a cultura, mesmo associada aos micronutrientes Co e Mo. Contudo quando combinado com baixas doses de $\mathrm{N}$ este eleva a produtividade para níveis iguais a adubação de $100 \mathrm{~kg} \mathrm{ha}{ }^{-1}$. E a suplementação com $\mathrm{S}$ também não propiciou aumento na produtividade.

3.2. Leitura do Índice de Suficiência de Nitrogênio (ISN), $\mathrm{SPAD}$ e teores de $\mathrm{N}$.

As leituras dos índices relativos de clorofila realizadas aos 20 DAE foram abaixo do ISN (90\%) nos tratamentos T1, T8 e T9 em relação ao T2 (100 $\mathrm{kg} \mathrm{ha}^{-1}$ na base), que é o padrão de ISN (100\%), observado na Tabela 4. Tanto T1, T8 e T9 não receberam adubação nitrogenada de base e, no caso do T8 e T9 a inoculação não conseguiu suprir a necessidade de $\mathrm{N}$ na fase inicial da planta. Aos 35 e 50 DAE, respectivamente, houve homogeneidade do ISN permanecendo acima de $90 \%$ para todos os tratamentos, em relação ao tratamento padrão nesta ocasião $(\mathrm{T} 15=160 \mathrm{~kg}$ ha ${ }^{1} \mathrm{de} \mathrm{N}$ ).

Ao se analisar o índice SPAD, os menores valores estão aos 20 DAE, com valores médios de 38,9 (Tabela 4) e os maiores aos 35 DAE, com média de 43,8, estabilizando-se 
aos 50 DAE, inclusive com uma pequena redução em relação a segunda. O teor de $\mathrm{N}$ na folha variou de 16,80 a $50,40 \mathrm{~g} \mathrm{~kg}$ ${ }^{1}$ para os tratamentos T5 e T13 respectivamente (Tabela 5), sendo que os tratamentos T13, T15 e T1 foram estatisticamente superiores aos demais, sendo principalmente para o T1 um efeito de concentração já que a planta produziu pouca massa seca, assim como a produtividade foi baixa.

Tabela 3: Contraste ortogonal para a produtividade de grãos no sistema de cultivo do pivô central, em plantas de feijoeiro Jalo precoce sobre diferentes tratamentos. Fazenda JF, Sinop-MT, 2011. Table 3: Orthogonal contrast to the grains produtivit in the central pivot system, in Jalo precoce bean plants on different treatments. Fazenda JF, Sinop-MT, 2011.

\begin{tabular}{lcc}
\hline Contrastes & P value & $\begin{array}{c}\text { Produtividade } \\
\left(\mathrm{kg} \mathrm{ha}^{-1}\right)\end{array}$ \\
\hline C1 - sem x com N & 0,000 & $1279 \times 1956$ \\
C2 - N até $100 \times 100 \mathrm{~kg} \mathrm{ha}^{-1}$ & 0,000 & $1879 \times 2340$ \\
C3 - N até $100 \mathrm{~kg} \mathrm{ha}^{-1}$, I x não I & 0,209 & $1794 \times 1963$ \\
C4 - não I e N até 100, B x C & 0,134 & $2138 \times 1847$ \\
C5 - I e com N, com x sem S & 0,140 & $1623 \times 1910$ \\
C6 - não I e com N, com x sem S & 0,864 & $2145 \times 2115$ \\
C7 - sem N, não I x I & 0,757 & $1226 \times 1306$ \\
C8 - I e sem N, com x sem CoMo & 0,694 & $1248 \times 1364$ \\
\hline
\end{tabular}

C1- T1, 8 e 9 x demais, C2 - T2 a 5, 7, 10, a 14 x T6 e 15, C3 - T2 e 3 x T4, 5 e $7, \mathrm{C} 4-\mathrm{T} 10$ a 14 x T2 a 5 e $7, \mathrm{C} 5-\mathrm{T} 11$ e 13 x T10, 12 e 14, C6 - T3, 4 and $6 \times \mathrm{T} 2,7$ e 15, C7 - T1 x T8 e 9 e C8 - T8 $\times$ T9. I = inoculado, $\mathrm{B}=$ maior parte do $\mathrm{N}$ na base e $\mathrm{C}=$ maior parte do $\mathrm{N}$ em cobertura.

C1- T1, 8 and $9 \times$ too much, C2 - T2 to $5,7,10$, to $14 \times$ T6 and $15, \mathrm{C} 3-\mathrm{T} 10$ to $14 \times$ T2 to 5 and $7, \mathrm{C} 3-\mathrm{T} 2$ and $3 \times \mathrm{T} 4,5$ and $7, \mathrm{C} 5-\mathrm{T} 11$ and $13 \times \mathrm{T} 10$, 12 and 14, C6 - T3, 4 and $6 \times$ T2, 7 and 15, C7 - T1 x T8 and 9 and C8- T8 $\mathrm{x}$ T9.I $=$ inoculated, $\mathrm{B}=$ most of the $\mathrm{N}$ in the base and $\mathrm{C}=$ most of the $\mathrm{N}$ in coverage.

É possível observar que o teor de $\mathrm{N}$ na planta e na folha não refletiram no teor de $\mathrm{N}$ no grão. Na planta no estádio de maturação o teor de $\mathrm{N}$ variou de $14,56 \mathrm{~g} \mathrm{~kg}^{-1}$ (T2) a $32,48 \mathrm{~g}$ $\mathrm{kg}^{-1}$ (T10) e estes resultados não tiveram aparentemente relação com as aplicações de N. O contrário é observado para o $\mathrm{N}$ nos grãos, com relação direta à aplicação de N. Os tratamentos com menor teor de $\mathrm{N}$ nos grãos (T1, T8, T9 e
T10), foram aqueles que não receberam $\mathrm{N}$ ou que receberam pequena dose. Já os maiores teores de $\mathrm{N}$ nos grãos foram nos tratamentos com adubação nitrogenada acima de $40 \mathrm{~kg} \mathrm{ha}^{-1}$, o que demonstra a capacidade do feijoeiro em absorver o $\mathrm{N}$ aplicado e usá-lo eficientemente, já que está adubação resultou em uma maior produtividade.

Tabela 4. Índices relativos de clorofila na primeira leitura foi realizada aos $20 \mathrm{DAE}\left(1^{\mathrm{a}} \mathrm{LT}\right)$, a segunda leitura aos $35 \mathrm{DAE}\left(2^{\mathrm{a}} \mathrm{LT}\right)$ e a última leitura 50 DAE $\left(3^{\mathrm{a}} \mathrm{LT}\right)$, e Índice de suficiência de nitrogênio (ISN) entre parênteses, no sistema de cultivo do pivô central, em plantas de feijoeiro Jalo precoce sobre diferentes tratamentos. Fazenda JF, Sinop-MT, 2011.

Table 4. Relative chlorophyll indices at first reading was performed at $20 \mathrm{DAE}\left(1^{\mathrm{a}} \mathrm{LT}\right)$, second reading at $35 \mathrm{DAE}\left(2^{\mathrm{a}} \mathrm{LT}\right)$ and the last reading 50 DAE $\left(3^{\mathrm{a}} \mathrm{LT}\right)$, and Nitrogen Suitability Index (ISN) in parentheses, in the central pivot Jalo precoce bean plants on different treatments. Fazenda JF, Sinop-MT, 2011.

\begin{tabular}{cccc}
\hline Tratamentos & $1^{\mathrm{a}} \mathrm{LT}$ & $2^{\mathrm{a}} \mathrm{LT}$ & $3^{\mathrm{a}} \mathrm{LT}$ \\
\hline T1 & $36,35_{(87 \%)}$ & $43,20_{(97 \%)}$ & $39,85_{(93 \%)}$ \\
T2 & $41,65_{(100 \%)}$ & $43,92_{(99 \%)}$ & $40,42_{(94 \%)}$ \\
T3 & $41,67_{(100 \%)}$ & $43,92_{(99 \%)}$ & $41,15_{(96 \%)}$ \\
T4 & $39,02_{(94 \%)}$ & $43,52_{(98 \%)}$ & $41,72_{(97 \%)}$ \\
T5 & $39,00_{(94 \%)}$ & $42,87_{(97 \%)}$ & $40,87_{(95 \%)}$ \\
T6 & $39,30_{(94 \%)}$ & $44,35_{(100 \%)}$ & $41,72_{(97 \%)}$ \\
T7 & $39,75_{(95 \%)}$ & $44,95_{(101 \%)}$ & $40,77_{(95 \%)}$ \\
T8 & $36,85_{(88 \%)}$ & $44,42_{(96 \%)}$ & $39,22_{(91 \%)}$ \\
T9 & $36,55_{(88 \%)}$ & $42,07_{(95 \%)}$ & $41,62_{(97 \%)}$ \\
T10 & $37,80_{(91 \%)}$ & $43,95_{(99 \%)}$ & $40,55_{(94 \%)}$ \\
T11 & $39,92_{(96 \%)}$ & $44,47_{(100 \%)}$ & $40,12_{(93 \%)}$ \\
T12 & $40,62_{(98 \%)}$ & $43,15_{(97 \%)}$ & $41,35_{(96 \%)}$ \\
T13 & $38,10_{(91 \%)}$ & $42,05_{(95 \%)}$ & $40,77_{(95 \%)}$ \\
T14 & $38,92_{(93 \%)}$ & $45,35_{(102 \%)}$ & $42,22_{(98 \%)}$ \\
T15 & $39,30_{(94 \%)}$ & $44,35_{(100 \%)}$ & $42,97_{(100 \%)}$ \\
\hline Média & 38,9 & $43_{, 8}$ & 41 \\
\hline
\end{tabular}

Tabela 5. Teor de nitrogênio foliar (NF), de nitrogênio nos grãos (NG), de nitrogênio na planta (NP), exportação de nitrogênio (EN) e eficiência agronômica de uso de N (EA), no sistema de cultivo do pivô central, em plantas de feijoeiro Jalo precoce sobre diferentes tratamentos. Fazenda JF, Sinop-MT, 2011.

Table 5. Leaf nitrogen content (NF), nitrogen in grains (NG), nitrogen in plant (NP), nitrogen export (EN) and agronomy efficiency use of $\mathrm{N}$ (EA), in the central pivot system, in Jalo precoce bean plants on different treatments. Fazenda JF, Sinop-MT, 2011.

\begin{tabular}{|c|c|c|c|c|c|c|}
\hline \multirow[t]{2}{*}{ Tratamentos } & $\mathrm{NG}$ & NP & NF & $\mathrm{EN}$ & N. APL & \multirow{2}{*}{$\frac{\mathrm{EA}}{\left(\mathrm{kg} \mathrm{kg}^{-1}\right)}$} \\
\hline & \multicolumn{3}{|c|}{ 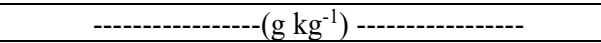 } & \multicolumn{2}{|c|}{------(kg ha'-1)------- } & \\
\hline $\mathrm{T} 1$ & $20,72 \mathrm{~b}$ & $28,56 \mathrm{a}$ & $36,40 \mathrm{a}$ & $26,95 \mathrm{~b}$ & 0 & - \\
\hline $\mathrm{T} 2$ & $34,16 \mathrm{a}$ & $14,56 \mathrm{~b}$ & $21,28 \mathrm{~b}$ & $72,68 \mathrm{a}$ & 100 & 8,82 \\
\hline $\mathrm{T} 3$ & $32,48 \mathrm{a}$ & $18,48 \mathrm{~b}$ & $29,68 \mathrm{~b}$ & $68,13 \mathrm{a}$ & 100 & 9,42 \\
\hline $\mathrm{T} 4$ & $31,36 \mathrm{a}$ & $15,12 \mathrm{~b}$ & $30,24 \mathrm{~b}$ & $60,74 \mathrm{a}$ & 100 & 6,57 \\
\hline $\mathrm{T} 5$ & 31,36 a & $17,36 \mathrm{~b}$ & $16,80 \mathrm{~b}$ & 53,63 a & 100 & 4,92 \\
\hline T6 & $35,84 \mathrm{a}$ & $24,64 \mathrm{a}$ & $23,52 \mathrm{~b}$ & $84,87 \mathrm{a}$ & 120 & 9,64 \\
\hline $\mathrm{T} 7$ & $31,36 \mathrm{a}$ & $17,36 \mathrm{~b}$ & $27,44 \mathrm{~b}$ & $62,15 \mathrm{a}$ & 100 & 7,13 \\
\hline $\mathrm{T} 8$ & $17,36 \mathrm{~b}$ & $16,24 b$ & $26,32 \mathrm{~b}$ & $20,98 \mathrm{~b}$ & 0 & - \\
\hline T9 & $20,16 \mathrm{~b}$ & $16,80 \mathrm{~b}$ & $26,32 \mathrm{~b}$ & $27,41 \mathrm{~b}$ & 0 & - \\
\hline $\mathrm{T} 10$ & $20,16 \mathrm{~b}$ & $32,48 \mathrm{a}$ & $25,20 \mathrm{~b}$ & $35,39 \mathrm{~b}$ & 20 & 28,01 \\
\hline $\mathrm{T} 11$ & $27,44 \mathrm{a}$ & $21,84 \mathrm{~b}$ & $28,00 \mathrm{~b}$ & $42,45 \mathrm{~b}$ & 40 & 8,16 \\
\hline $\mathrm{T} 12$ & $31,36 \mathrm{a}$ & $16,24 \mathrm{~b}$ & $30,80 \mathrm{~b}$ & $53,86 \mathrm{a}$ & 40 & 12,48 \\
\hline T13 & $26,88 \mathrm{a}$ & $19,04 \mathrm{~b}$ & $50,40 \mathrm{a}$ & $44,22 \mathrm{~b}$ & 80 & 5,83 \\
\hline T14 & $32,48 \mathrm{a}$ & $26,32 \mathrm{a}$ & $32,48 \mathrm{~b}$ & 57,12 a & 60 & 9,37 \\
\hline $\mathrm{T} 15$ & $31,92 \mathrm{a}$ & $19,04 \mathrm{~b}$ & $45,36 \mathrm{a}$ & $73,43 \mathrm{a}$ & 160 & 6,70 \\
\hline CV (\%) & 26,82 & 38,26 & 36,10 & 33,90 & - & - \\
\hline Média & 28,34 & 20,27 & 30,02 & 52,26 & - & - \\
\hline
\end{tabular}

As médias seguidas de mesma letra nas colunas, não diferem entre si pelo teste de Scott-Knott a 5\% de probabilidade.

The averages followed by the same letter in the columns do not differ by Scott-Knott's test at $5 \%$ probability. 
A exportação de $\mathrm{N}$ teve elevada relação com o teor de $\mathrm{N}$ no grão e produtividade (Tabela 6) e os valores seguiram o mesmo padrão, apresentando os menores valores até a dose de $40 \mathrm{~kg} \mathrm{ha}^{-1}$ de N. O tratamento T11 mesmo recebendo 40 $\mathrm{kg} \mathrm{ha}^{-1}$ apresentou baixa exportação, possivelmente vinculado a aplicação total deste em semeadura. Já o tratamento T13 mesmo recebendo $80 \mathrm{~kg} \mathrm{ha}^{-1}$ também apresentou baixa exportação. Nas doses mais elevadas de N (T6 e T15) é possível observar altas produtividades aliadas a grãos ricos em N, o que configurou exportação de aproximadamente 79 $\mathrm{kg} \mathrm{ha}{ }^{-1}$ de N. A eficiência agronômica nos tratamentos utilizados variou de 4,92 a 28,01 $\mathrm{kg}$ de grão por $\mathrm{kg}$ de $\mathrm{N}$ aplicado, sendo as maiores eficiências encontradas naqueles tratamentos com doses menores de $\mathrm{N}$.

\section{DISCUSSÃO}

Avaliar a altura de inserção da primeira vagem é de fundamental importância para uma melhor resposta a colheita mecanizada da cultura. A não resposta pode estar vinculada a esta característica não estar vinculada a práticas culturais, como a adubação utilizada, sendo uma resultante da predisposição genética da cultivar (NASCIMENTO et al., 2009). Os mesmos autores Também não observaram resposta à aplicação de diferentes fertilizantes para a altura de inserção de primeira vagem. No presente trabalho esta variou de 16,13 a $21,27 \mathrm{~cm}$, sendo a média dos tratamentos de $19 \mathrm{~cm}$ que, segundo Meira et al. (2005), está dentro das características da cultura.

A quantidade de grãos por vagens $(\mathrm{GV})$ não foi influenciada pelos tratamentos e não mostrou correlação com nenhum dos outros parâmetros estudados o que corrobora com dados obtidos por Chidi et al. (2002), que não obtiveram alterações na quantidade de grãos por vagem nos dois anos de cultivo, utilizando duas formas de adubação nitrogenada (via solo e via foliar), ressaltando que essa característica está mais relacionada com o genótipo da cultivar.
Os resultados obtidos referentes à altura de plantas mostraram a necessidade de se aplicar $\mathrm{N}$ na cultura do feijoeiro, propiciando uma planta de maior porte. A AP foi influenciada pelo maior fornecimento de $\mathrm{N}$, independente da fonte utilizada. A inoculação por si só não é suficiente para aumento da AP, mesmo com aplicação de $\mathrm{Co}+\mathrm{Mo}$, contudo se observa que quando esta é associada a baixas doses na base foram suficientes para as necessidades da cultura, em contra partida se observa que a dose de apenas $20 \mathrm{~kg}$ na base sem a inoculação não foi suficiente, com a planta apresentando menor AP. Meira et al. (2005) não encontraram diferença significativa na AP avaliando doses e épocas de aplicação de N, já Salgado (2012) estudando o efeito do N no feijoeiro constataram um maior tamanho de planta em maiores concentrações de $\mathrm{N}$ no solo.

Uma possível explicação para a massa seca do tratamento $\mathrm{T} 12$ (inoculado $+40 \mathrm{~kg} \mathrm{ha}^{-1}$ de N e $24 \mathrm{~kg} \mathrm{ha}^{-1}$ de S na base + CoMo) ter sido alta pode ser a fonte de $\mathrm{N}$ utilizada, pois é sabido que o sulfato de amônio possibilita um maior aproveitamento do $\mathrm{N}$ aplicado, sendo este também o único tratamento que recebeu $\mathrm{S}$ na aplicação de base. Como já observado nas demais características, apenas a inoculação e a aplicação de Co e Mo, aparentemente não disponibilizam a quantidade necessária de $\mathrm{N}$ para a planta, que veio a contribuir com a menor massa de plantas em T1, T7 e T8. Oliveira et al. (2004) verificaram um aumento no acúmulo de matéria seca conforme se aumentava a dose de $\mathrm{N}$, resultado que concorda com os dados obtidos no presente trabalho.

$\mathrm{O} \mathrm{N}$ é um nutriente indispensável para a molécula de clorofila, fazendo parte de sua constituição. Assim indispensável para o bom desenvolvimento da mesma, isto pode ser observado pelo maior porte e maior massa das plantas que receberam N. A maior disponibilidade de $\mathrm{N}$ possivelmente colaborou para uma maior produção de clorofila, assim se obtendo uma maior produção de fotoassimilados, mais energia para planta, resultando em plantas de maior porte (AL e MS).

Tabela 6. Coeficientes de correlação de Pearson entre os parâmetros avaliados, produtividade (PD), massa de 100 grãos (M100), altura de planta (AP), altura de inserção da primeira vagem (IPV), número de vagens por planta (VP), número de grãos por vagens $(\mathrm{GV})$, massa seca da planta inteira (MS), Índice de SPAD na $1^{\mathrm{a}}$ Leitura ( $1^{\mathrm{a}}$ LT.), $2^{\mathrm{a}}$ Leitura $\left(2^{\mathrm{a}} \mathrm{LT}\right.$.) e $3^{\mathrm{a}}$ Leitura $\left(3^{\mathrm{a}} \mathrm{LT}\right.$.), teor de nitrogênio no grão (NG), na folha (NF) e na planta (NP) e exportação de nitrogênio (EN), no sistema de cultivo do pivô central, em plantas de feijoeiro Jalo precoce sobre diferentes tratamentos. Fazenda JF, Sinop-MT, 2011.

Table 6. Pearson correlation coefficients among the evaluated parameters, productivity (PD), mass of 100 grains (M100), plant height (AP), height of first pod insertion (IPV), number of pods per plant (VP), number of grains per pods (GV), SPAD index in 1st Reading ( $1^{\mathrm{a}} \mathrm{LT}$.), 2nd Reading ( $\left.2^{\mathrm{a}} \mathrm{LT}\right)$, 3rd Reading $\left(3^{\mathrm{a}} \mathrm{LT}\right)$, nitrogen content in grain (NG), in leaf (NF) and in plant (NP) and nitrogen exportation (EN), in central pivot cultivation system, in bean plants Jalo precoce on different treatments. Fazenda JF, Sinop-MT, 2011.

\begin{tabular}{|c|c|c|c|c|c|c|c|c|c|c|c|c|c|c|}
\hline & PD & M100 & $\mathrm{AP}$ & IPV & VP & $\mathrm{GV}$ & MS & $1^{\mathrm{a}} \mathrm{LT}$ & $2^{\mathrm{a}} \mathrm{LT}$ & $3^{\mathrm{a}} \mathrm{LT}$ & NG & $\mathrm{NF}$ & NP & EN \\
\hline PD & - & $0,298^{*}$ & $0,572 * *$ & $-0,209$ & $0,726 * *$ & 0,176 & $0,592 * *$ & $0,338 * *$ & 0,091 & 0,072 & $0,355^{* *}$ & $-0,078$ & $-0,120$ & $0,759 * *$ \\
\hline M100 & & - & 0,183 & $-0,035$ & $0,280^{*}$ & $-0,144$ & $0,354 * *$ & $-0,160$ & $-0,079$ & $-0,050$ & 0,157 & 0,194 & 0,022 & $0,279 *$ \\
\hline $\mathrm{AL}$ & & & - & 0,136 & $0,566^{* *}$ & $-0,071$ & $0,494 * *$ & 0,226 & 0,232 & 0,103 & 0,204 & 0,100 & 0,016 & $0,410 * *$ \\
\hline IPV & & & & - & $-0,466^{* *}$ & $-0,143$ & $-0,201$ & $-0,143$ & $-0,073$ & 0,077 & $-0,230$ & 0,193 & 0,085 & $-0,280^{*}$ \\
\hline VP & & & & & - & 0,027 & $0,674 * *$ & $0,314^{*}$ & 0,110 & 0,009 & 0,225 & $-0,026$ & $-0,076$ & $0,542 * *$ \\
\hline GV & & & & & & - & 0,019 & 0,123 & $-0,077$ & $-0,016$ & 0,103 & $-0,223$ & 0,054 & 0,140 \\
\hline MS & & & & & & & - & $0,279 *$ & 0,075 & 0,067 & $0,335 * *$ & $-0,069$ & $-0,060$ & $0,516^{* *}$ \\
\hline $1^{\mathrm{a}} \mathrm{LT}$ & & & & & & & & - & 0,013 & 0,202 & $0,262^{*}$ & 0,016 & $-0,095$ & $0,353 * *$ \\
\hline $2^{\mathrm{a}} \mathrm{LT}$ & & & & & & & & & - & $0,319^{*}$ & 0,130 & $-0,064$ & 0,095 & 0,104 \\
\hline $3^{\mathrm{a}} \mathrm{LT}$ & & & & & & & & & & - & 0,097 & 0,064 & 0,077 & 0,100 \\
\hline NG & & & & & & & & & & & - & $-0,169$ & $-0,166$ & $0,846^{* *}$ \\
\hline NF & & & & & & & & & & & & - & 0,093 & $-0,202$ \\
\hline NP & & & & & & & & & & & & & - & $-0,164$ \\
\hline $\mathrm{EN}$ & & & & & & & & & & & & & & - \\
\hline
\end{tabular}

*Significativo a $5 \%$ pelo teste $\mathrm{F}(\mathrm{P}<0,05) . * *$ Significativo a $1 \%$ pelo teste $\mathrm{F}(\mathrm{P}<0,01)$

* Significant at $5 \%$ by the $\mathrm{F}$ test $(\mathrm{P}<0.05)$. ** Significant at $1 \%$ by the $\mathrm{F}$ test $(\mathrm{P}<0.01)$ 
Com as plantas possuindo maior porte, se tem mais condições para a produção de vagens, isto é observado pela correlação positiva entre as variáveis AP e MS com o VP. Verificou-se que é necessária a aplicação de $\mathrm{N}$ total ou parcial (ao menos 40\%) na semeadura para a melhor resposta desta característica, o que pode estar relacionado a necessidade de $\mathrm{N}$ em sistemas de plantio direto sobre a palha de milho, devido a alta relação $\mathrm{C} / \mathrm{N}$, que mobiliza, temporariamente, grande quantia de N. Andreotti et al. (2005), não obtiveram efeito da fonte e da forma de aplicação do $\mathrm{N}$ para o número de vagens por planta. Andrade et al. (2004), trabalhando com níveis de adubação e com cultivares, obtiveram efeito da adubação nitrogenada para esta característica, constatando que quanto maior a dose melhores eram os resultados.

A massa de 100 grãos foi maior somente nos tratamentos com elevada aplicação de $\mathrm{N}\left(>120 \mathrm{~kg} \mathrm{ha}^{-1}\right)$, a exceção foi o tratamento $\mathrm{T} 13$, a menor dose de $\mathrm{N}\left(80 \mathrm{~kg} \mathrm{ha}^{-1}\right)$ foi compensada pelo efeito dos demais nutrientes aplicados $(\mathrm{S}$, Co e Mo) associados à inoculação. Isto se somou ao fato das plantas deste tratamento terem uma baixa produção de vagens e consequentemente menor número de grãos por planta, assim os fotoassimilados foram translocados para os grãos, aumentando sua massa. Contudo isto não foi suficiente para que a produtividade da parcela fosse influenciada, com as plantas obtendo baixa produtividade. Estes resultados mostram a importância da aplicação de $\mathrm{N}$, pois as melhores respostas foram encontradas nas maiores doses totais de $\mathrm{N}$. Stone; Moreira (2001) constataram que a massa de grãos responde significativamente ao aumento nas doses de $\mathrm{N}$, resultante da grande influência do $\mathrm{N}$, pois quando se tem deficiência de $\mathrm{N}$ as sementes são pequenas, tendo como consequência redução na produção de massa. Andreotti et al. (2005) observaram que não houve efeito da fonte e da forma de aplicação do $\mathrm{N}$ para tal característica.

$\mathrm{O}$ fato da produtividade não ser afetada pela inoculação, quando está é aplicada sem complemento de $\mathrm{N}$, pode estar vinculada a necessidade inicial de $\mathrm{N}$, num momento em que a simbiose ainda não está bem estabelecida, não conseguindo atender esta demanda. Isto pode ser observado nos tratamentos que receberam apenas $20 \mathrm{~kg} \mathrm{ha}^{-1}$ de $\mathrm{N}$ na base associados a inoculação e se equiparam aos tratamentos que receberam $100 \mathrm{~kg} \mathrm{ha}^{-1}$. Ficando evidente que sistemas de cultivo em que se cultiva a soja na safra, o milho segunda safra e o feijoeiro sobre palhada de milho, uma dose de $\mathrm{N}$ no arranque deve ser priorizada para o melhor desenvolvimento inicial da cultura, com melhores índices de clorofila como no T2 e T3 (Tabela 5) e melhores produtividades finais.

$\mathrm{O}$ fornecimento de $\mathrm{S}$ não foram efetivos para que tenha um aumento na produção de grãos, isto se deve ao solo já possuir quantidade suficiente para atender as demandas da cultura. Outro ponto que poderia influenciar seria o maior aproveitamento do $\mathrm{N}$ da fonte sulfato de amônio quando comparado a ureia. Contudo isto não ocorreu possivelmente pelo cuidado na aplicação dos fertilizantes, em que foram aplicadas laminas de água logo após a aplicação de $\mathrm{N}$, procedimento que possivelmente foi efetivo na redução das perdas de $\mathrm{N}$ por volatilização.

Os componentes de produção que mais se correlacionaram com os incrementos obtidos na produtividade foram a M100, VP e AP (Tabela 6). Pelegrin et al. (2009) afirmam que aplicar $20 \mathrm{~kg} \mathrm{ha}^{-1}$ de $\mathrm{N}$ ou mais proporciona acréscimos significativos na produtividade, quando comparadas a tratamentos sem adubação nitrogenada.

$\mathrm{Na}$ região, a produção de feijão de inverno é, muitas vezes, sobre palhada de milho segunda safra e, a aplicação de doses de arranque próximas a $40-50 \mathrm{~kg} \mathrm{ha}^{-1}$ ou mais são necessárias para evitar a imobilização de $\mathrm{N}$ no solo. No presente caso, a palha residual do milho era de aproximadamente $5000 \mathrm{~kg} \mathrm{ha}^{-1}$ que apresenta, segundo a literatura, relação $\mathrm{C} / \mathrm{N}$ que varia de 45 a 70 (SILVA et al., 2008; CALONEGO et al., 2012). Neste contexto, sabendo que a concentração de $\mathrm{N}$ na palha de milho é próxima a $6 \mathrm{~g}$ $\mathrm{kg}^{-1}$ (SILVA et al., 2008; LANGE et al., 2009) e assumindo $\mathrm{C} / \mathrm{N}$ na palha de milho de 60 , teríamos na palha 30 e $1800 \mathrm{~kg}$ $\mathrm{ha}^{-1}$ de $\mathrm{N}$ e $\mathrm{C}$, respectivamente. Para baixar a relação $\mathrm{C} / \mathrm{N}$ para próximo de 25:1, que é indicada com a faixa limítrofe de equilíbrio entre mineralização e imobilização, teria que ser adicionado ao sistema no mínimo $45 \mathrm{~kg} \mathrm{ha}^{-1}$ de $\mathrm{N}$, que somados os 30 da palha do milho resultariam em $75 \mathrm{~kg}$ de N, proporcionando uma relação $\mathrm{C} / \mathrm{N}$ teórica de 24 , disponibilizando $\mathrm{N}$ ao feijoeiro. Isto justifica a resposta do feijoeiro às doses próximas ou maiores que $40-50 \mathrm{~kg} \mathrm{ha}^{-1}$ no arranque (T2, T3 e T15), com produtividades também maiores $\left(2200 \mathrm{~kg} \mathrm{ha}^{-1}\right)$, corroborando com o trabalho de Lange et al. (2017).

$\mathrm{O}$ teor de $\mathrm{N}$ na folha na maioria dos tratamentos ficou abaixo do considerado ideal para a cultura, de 30-50 $\mathrm{g} \mathrm{kg}^{-1}$ (MALAVOLTA et al., 1997). A explicação para o alto teor de $\mathrm{N}$ no Controle, quando comparado aos demais que receberam adubação nitrogenada, é o efeito de diluição, pois no tratamento controle as plantas apresentaram porte baixo, menor número de vagens e massa de planta reduzida (Tabela 2). Com isto mesmo com menor disponibilidade de $\mathrm{N}$ no solo, o teor de $\mathrm{N}$ foi mais elevado, pois o elemento não foi diluído entre as demais partes da planta. Em contrapartida, observa-se menor exportação, apenas $26 \mathrm{~kg} \mathrm{ha}^{-1}$, resultado da carência de $\mathrm{N}$ neste tratamento.

Estes valores demonstram que em torno de $55 \mathrm{~kg} \mathrm{ha}^{-1}$ de $\mathrm{N}$ (79 kg ha-1 de $\mathrm{N}$ exportado nos tratamentos mais produtivos e $24 \mathrm{~kg} \mathrm{ha}^{-1}$ no tratamento controle) foram fornecidos pelo adubo nitrogenado, corroborando com a taxa de aproveitamento do $\mathrm{N}$ pelo feijoeiro, que segundo Brito et al. (2011), para as suas condições foi na média de $60,6 \%$ aproximadamente. Levando em consideração sistemas que almejam altas produtividades, como no caso do estudo, com alto investimento em irrigação, solos corrigidos e controle adequado de pragas e doenças, os manejos mais promissores de $\mathrm{N}$ na cultura ocorreram nos tratamentos 2,3 e 6 , que apresentaram EA maiores que oito e produtividades acima de $2000 \mathrm{~kg} \mathrm{ha}^{-1}$.

De acordo com Sant'ana et al. (2010), as vantagens do clorofilômetro são o tempo gasto para análise, o baixo custo, a não influência do consumo de luxo de $\mathrm{N}$, tendo verificado para feijoeiro que o acréscimo no valor do índice SPAD acompanha as doses de $\mathrm{N}$ aplicadas e correlaciona-se linear e positivamente com a idade das plantas, até certo limite. Os mesmos autores observaram índice máximo de 47 , próximo aos maiores valores observados no presente estudo.

A homogeneidade nas leituras SPAD e no índice de suficiência de $\mathrm{N}$ nas leituras aos 35 e 50 DAE pode ser atribuída ao início da mineralização do $\mathrm{N}$ que estava presente na palhada do milho, sendo disponibilizado para absorção pela cultura após alguns dias. A mineralização é um processo 
lento, porém pode ter sido estimulada pelo pequeno revolvimento que houve na linha de semeadura aliada a condição de água disponível e alta temperatura.

Além disso, a segunda leitura foi realizada cinco dias após a aplicação de $\mathrm{N}$ em cobertura, proporcionando aos tratamentos que receberam $\mathrm{N}$ nesta época aumento do índice de clorofila. Na leitura aos $50 \mathrm{DAE}$, o maior valor foi para o $\mathrm{T} 15$, com aplicação de $100 \mathrm{~kg} \mathrm{ha}^{-1}$ na cobertura, precedido de $60 \mathrm{~kg} \mathrm{ha}^{-1}$ na semeadura, possivelmente havia ainda $\mathrm{N}$ disponível no solo remanescente da cobertura aos 30 DAE e maior teor de $\mathrm{N}$ na planta, devido ao fornecimento adequado do $\mathrm{N}$, o que está de acordo com os teores de $\mathrm{N}$ foliares (Tabela 5).

A diminuição no valor da segunda para terceira leitura pode ser explicado pelo fato da cultivar ter ciclo de 72 dias e a leitura aos $50 \mathrm{DAE}$, sendo assim já começo o processo de translocação de $\mathrm{N}$ para o grão, o que está de acordo com Barbosa Filho et al. (2008), que observaram estabilização das leituras após o florescimento das plantas.

Em relação às correlações, obteve-se correlação positiva entre a PD e M100, AP, VP, MS, $1^{\mathrm{a}} \mathrm{LT}$, NG e EN, conforme Tabela 6. Ou seja, plantas que obtiveram uma maior altura proporcionaram um maior número de vagens, pelo fato de plantas mais altas conterem maior número de gemas florais e consequentemente maior número de vagens, e o maior número de vagens teve correlação negativa com a altura de inserção da primeira vagem, o que nos remete a inferir que plantas com vagens na região do "baixeiro" tem maior quantidade de vagens, pelo fato de possuírem vagens desde as primeiras gemas. Salienta-se que esta nem sempre é uma característica desejável, pelo fato de vagens muitos baixas dificultarem a colheita mecanizada. No presente caso, a menor média de altura de inserção da primeira vagem foi de $16,13 \mathrm{~cm}$, o que não dificulta a colheita.

Outros fatores que mostraram correlação foram o teor de clorofila aos 20 DAE, e uma maior massa seca, isto nos remete a plantas maiores com maior interceptação da luminosidade, gerando maior quantidade de fotoassimilados, os quais são translocados para os grãos, gerando assim grãos mais nutridos (maior teor de $\mathrm{N}$ no grão), maior número de vagens pelo fato da planta estar com maior disponibilidade de fotoassimilados e assim um menor abortamento espontâneo das flores da planta e grãos com maior massa, sendo que a massa dos grãos é uma das principais responsáveis pelo aumento na produtividade. No estudo a maior M100 foi no tratamento $\mathrm{T} 15$, tratamento que obteve alta produtividade.

\section{CONCLUSÕES}

O feijoeiro é altamente responsivo a adubação nitrogenada.

O uso da inoculação de forma isolada não é eficiente para incrementos na produtividade, mas quando associada a pequenas doses de nitrogênio contribui para o aumento da produtividade, com menores custos.

O fornecimento de nitrogênio resulta em melhoria nos fatores de produção, nos teores de nitrogênio na planta, nos grãos e nas folhas e aumento da produtividade.

\section{AGRADECIMENTOS}

A Fapemat (Edital Universal, processo No. 300111/2010), por ter financiado o projeto, ao senhor Jaime Farinon, por ceder a área e auxiliar na condução dos trabalhos de campo, ao laboratório de Solos da UFMT/Sinop - MT e todos os acadêmicos do curso de Agronomia que participaram do trabalho.

\section{REFERÊNCIAS}

ALMEIDA, C.; CARVAlHO, M. A. C.; ARF, O.; SÁ, M. E.; BUZETTI, S. Uréia em cobertura e via foliar em feijoeiro. Scientia Agricola, Jaboticabal, v. 57, n. 2, p. 293-298, 2000. DOI: http://dx.doi.org/10.1590/S010390162000000200016

ANDRADE, C. A. B.; PATRONI, S. M. S.; CLEMENTE, E.; SCAPIM, C. A. Produtividade e qualidade nutricional de cultivares de feijão em diferentes adubações. Ciência e Agrotecnologia, Lavras, v. 28, n. 5, p. 1077-1086, 2004. DOI: http://dx.doi.org/10.1590/S141370542004000500015

ANDREOTTI, M.; NAVA, I. A.; WIMMER NETO, L.; GUIMARÃES, V. F.; FURLANI JUNIOR, E. Fontes de nitrogênio e modos de adubação em cobertura sobre a produtividade de feijão (Phaseolus vulgaris L.) na "safra das águas". Acta Scientiarum Agronomy, Maringá, v. 27, n. 4, p. 595-602, 2005. DOI: http://dx.doi.org/10.4025/actasciagron.v27i4.1306.

BARBOSA FILHO, M. P.; COBUCCI, T.; FAGERIA, N. K.; MENDES, P. N. Época de aplicação de nitrogênio no feijoeiro irrigado monitorado com auxilio de monitor portátil. Ciência e Agrotecnologia, Lavras, v. 33, n. 2, p. 425-431, 2009. DOI: http://dx.doi.org/10.1590/S141370542009000200010

BARBOSA FILHO, M. P.; COBUCCI, T.; FAGERIA, N. K.; MENDES, P. N. Determinação da necessidade de adubação nitrogenada de cobertura no feijoeiro irrigado com auxílio do clorofilômetro portátil. Ciência Rural, Santa Maria, v. 38, n. 7, p. 1843-1848, 2008. DOI: http://dx.doi.org/10.1590/S0103-84782008000700007

BARBOSA FILHO, M. P.; SILVA, O. F. Adubação de cobertura do feijoeiro irrigado com ureia fertilizante em plantio direto. Informações Agronômicas no 932001.

BASSAN, D. A. Z.; ARF, O.; BUZETTI, S.; CARVALHO, M. A. C.; SANTOS, N. C. B.; SÁ, M. E. Inoculação de sementes e aplicação de nitrogênio e molibdênio na cultura do feijão de inverno: produção e qualidade fisiológica de sementes. Revista Brasileira de Sementes, Londrina, v. 23, n. 1, p. 76-83, 2001.

BINOTTI, F. F. S.; ARF, O.; ROMANINI JUNIOR, A.; FERNANDES, F. A.; SÁ, M. E.; BUZETTI, S. Manejo do solo e da adubação nitrogenada na cultura de feijão de inverno e irrigado. Bragantia, Campinas, v. 66, n. 1, p. 121-129, 2007. DOI: http://dx.doi.org/10.1590/S000687052007000100015

BRITO, M. M. P.; MURAOKA, T.; SILVA, E. C. Contribuição da fixação biológica de nitrogênio, fertilizante nitrogenado e nitrogênio do solo no desenvolvimento de feijão e caupi. Bragantia, Campinas, v. 70, n. 1, p. 206-215, 2011. DOI: http://dx.doi.org/10.1590/S0006-87052011000100027

CALONEGO, J. C.; GIL, F. C.; ROCCO, V. F.; SANTOS, E. A. Persistência e liberação de nutrientes da palha de milho, braquiária e labe-labe. Bioscience Journal, Uberlândia, v. 28, n. 5, p. 770-781, 2012.

CAVALLI, E.; LANGE, A.; BUCHELT, A. C.; CAVALLI, C.; WRUCK, F. J. Subdivision of nitrogen fertilization in 
irrigated bean culture in the Middle-North of Mato Grosso, Brazil. Nativa, v. 4, n. 5, p. 296-302, 2016.

CERETTA, C. A.; PAVINATO, A.; PAVINATO, P. S.; MOREIRA, I. C. L.; GIROTTO, E.; TRENTIN, E. E. Micronutrientes na soja: produtividade e análise econômica. Ciência Rural, Santa Maria, v. 35, n. 3, p. 576-581, 2005. DOI: http://dx.doi.org/10.1590/S010384782005000300013

CHIDI, S. N.; SORATTO, R. P.; SILVA, T. R. B.; ARF, O.; SÁ, M. E.; BUZZETTI, S. Nitrogênio via foliar e em cobertura em feijoeiro irrigado. Acta Scientiarum Agronomy, Maringá, v. 24, n. 5, p. 1391-1395, 2002.

FAGERIA, N. K.; BALIGAR, V. C. Enhancing nitrogen use efficiency in crop plants. Advances in Agronomy, v. 88, p. 97-185, 2005.

FARINELLI, R.; LEMOS, L. B. Produtividade, eficiência agronômica, características nutricionais e tecnológicas do feijão adubado com nitrogênio em plantio direto e convencional. Bragantia, Campinas, v. 69 , n. 1, p. 165172, 2010. DOI: http://dx.doi.org/10.1590/S000687052010000100021

FERREIRA, N. A.; ARF, O.; CARVALHO, M. A. C.; ARAÚJO, R. S.; SÁ, M. E.; BUZETTI, S. Estirpes de Rhizobium Tropici na inoculação do feijoeiro. Scientia Agricola, Jaboticabal, v. 57, n. 3, p. 507-512, 2000. DOI: http://dx.doi.org/10.1590/S0103-90162000000300021

GOMES JUNIOR, F. G.; SÁ, M. E.; MURAISHI, C. T. Adubação nitrogenada no feijoeiro em sistema de semeadura direta e preparo convencional do solo. Acta Scientiarum Agronomy, Maringá, v. 30, n. 5, p. $673-$ 680, 2008.2 DOI: http://dx.doi.org/10.4025/actasciagron.v30i5.5967

LANGE, A.; BUCHELT, A. C.; KOBELISKI, O. A.; CAVALLI, E.; WRUCK, F. J.; CAIONE, G. Nitrogênio, enxofre, micronutrientes e inoculante no cultivo do feijoeiro irrigado no estado de Mato Grosso. Scientific Electronic Archives, v. 10, n. 1, p. 42-50, 2017.

LANGE, A.; CABEZAS, W. A. R. L.; TRIVELIN, P. C. O. Adubação nitrogenada e palhada no milho após soja em sistema semeadura direta. Revista Brasileira de Milho e Sorgo, Sete Lagoas, v. 8, n. 1, p. 57-68, 2009. DOI: http://dx.doi.org/10.18512/1980-6477/rbms.v8n1p57-68

MALAVOLTA, E.; VITTI. G. C.; OLIVEIRA, A. S. Avaliação do estado nutricional das plantas: princípios e aplicações. 2. ed. Potafós: Piracicaba, 1997, $319 \mathrm{p}$.

MEIRA, F. A.; SÁ, M. E.; BUZETTI, S.; ARF, O. Doses e épocas de aplicação de nitrogênio no feijoeiro irrigado cultivado em plantio direto. Pesquisa agropecuária brasileira, Brasília, v. 40, n. 4, p. 383-388, 2005.
NASCIMENTO, M. S.; ARF, O.; BARBOSA, G. F.; BUZETTI, S.; NASCIMENTO, R. S.; CASTRO, R. M. Nitrogênio em cobertura e molibdênio via foliar em feijoeiro de inverno no sistema plantio direto, II características agronômicas e produtividade. Scientia Agraria, Curitiba, v. 10, n .5, p. 351-358, 2009. DOI: http://dx.doi.org/10.5380/rsa.v10i5.15187

OLIVEIRA, R. M. B.; OLIVEIRA, F. A.; GUEDES, K. Fertilização nitrogenada e irrigação na cultura do feijão (Phaseolus vulgaris L) em casa de vegetação. Revista de Biologia e Ciências da Terra, v. 4, n. 2, p. 1-6, 2004.

PELEGRIN, D. E. R.; MERCANTE, F. M.; OTSUBO, I. M. N.; OTSUDO, A. A. Resposta da cultura do feijoeiro à adubação nitrogenada e à inoculação com rizóbio. Revista Brasileira de Ciências do Solo, Viçosa, v. 33, n. 1 p. 219-226, 2009. http://dx.doi.org/10.1590/S0100-06832009000100023

SALGADO, F. H. M. Efeito do nitrogênio em feijão cultivado em terras altas no sul do estado de Tocantins. Ambiência Guarapuava, Guarapuava, v. 8, n. 1, p. 125 136 , 2012.

DOI:

http://dx.doi.org/10.5777/ambiencia.2012.01.10

SANT'ANA, E. V. P.; SANTOS, A. B.; SILVEIRA, P. M. Adubação nitrogenada na produtividade, leitura SPAD e teor de nitrogênio em folhas de feijoeiro. Pesquisa Agropecuária tropical, Goiânia, v. 40, n. 4, p. 491-496, 2010. DOI: http://dx.doi.org/10.5216/pat.v40i4.6320

SILVA, E. C.; MURAOKA, T.; ESPINAL, F. S. C.; BUZETTI, S.; TRIVELIN, P. C. O. Utilização do nitrogênio da palha de milho e de adubos verdes pela cultura do milho. Revista Brasileira de Ciência do Solo, Viçosa, v. 32(ne), p. 2853-2861, 2008. DOI: http://dx.doi.org/10.1590/S0100-06832008000700032

SILVA, F. C. Manual de análises químicas do solos, plantas e fertilizantes. Brasília, DF. 2. ed. rev. ampl. Embrapa Informação Tecnológica, 2009, 627p.

STONE, L. F.; MOREIRA, J. A. A. Resposta do feijoeiro ao nitrogênio em cobertura, sob diferentes lâminas de irrigação e preparos do solo. Pesquisa Agropecuária Brasileira, Brasília, v. 36, n. 3, p. 473-481, 2001.

VITTI, G. C.; TAVARES, J. E.; LUZ, P. H. C.; FAVARIN, J. L.; COSTA, M. C. G. Influencia da mistura de sulfato de amônio com ureia sobre a volatilização de nitrogênio amoniacal. Revista Brasileira de Ciência do Solo, v. 26, p. $663-671,2002$. 